\title{
OPTIMIZATION OF MEDIA FOR ANTIMICROBIAL COMPOUNDS PRODUCTION BY BACILLUS SUBTILIS
}

\author{
J.A. Grahovac, Z.Z. RončEvić, I.Ž. TadiJan, A.I. Jokić* and J.M. Dodić \\ Department of Biotechnology and Pharmaceutical Engineering, Faculty of Technology, University of Novi Sad, \\ Blvd. cara Lazara 1, RS-21000 Novi Sad. Serbia \\ (Received: 9 January 2014; accepted: 24 April 2014)
}

Bacillus subtilis is one of the most important producers of diverse antimicrobial compounds. This bacterium grows and produces antibiotics on different substrates. The increase of the antibiotics yield can be achieved by changing the conditions of cultivation and the composition of the culture media. In this study, response surface methodology was used for optimization of glycerol, sodium nitrite, and phosphate content in media for production of antibiotics effective against Staphylococcus aureus. As biosynthesis strain Bacillus subtilis ATCC 6633 was used. The developed model predicts that the maximum inhibition zone radius $(38.08 \mathrm{~mm})$ against Staphylococcus aureus and minimal amount of residual nutrients (glycerol $1.75 \mathrm{~g} \mathrm{l}^{-1}$, nitrogen $0.21 \mathrm{~g} \mathrm{l}^{-1}$, phosphorus $0.18 \mathrm{~g}^{-1}$ ) are achieved, when the initial content of glycerol, sodium nitrite, and phosphate are $49.99 \mathrm{~g} \mathrm{l}^{-1}, 1.00 \mathrm{~g} \mathrm{l}^{-1}$, and $5.00 \mathrm{~g} \mathrm{l}^{-1}$, respectively.

Keywords: Bacillus subtilis, antimicrobial compounds, optimization, RSM

The dissemination of multidrug-resistant pathogenic microorganisms represents a serious problem worldwide. Staphylococcus aureus is one of the most common causes of diseases, and the main threat to human health is the emergence of resistant forms of this bacteria. In recent years, the increasing number of Staphylococcus infections has caused an urgent need to discover and develop new antimicrobial agents (KUTA et al., 2009; TABBENE et al., 2009).

Microorganisms represent inexhaustible source of bioactive compounds. Producing more than 70 different metabolites with antimicrobial action, Bacillus subtilis is one of the most important producers (Todorova \& Kozhunarova, 2010). Bacillus subtilis is beneficial is many ways, including industrial applications. It is used to produce many antibiotics with an amazing variety of structures and mechanisms of action. This bacterium is also being used to produce fungicides, insecticides, and enzymes. According to their biosynthetic pathway, these metabolites can be grouped into two different classes: the first class comprises ribosomal synthesized peptides, whereas the second class comprises small microbial peptides synthesized enzymatically by non-ribosomal pathways (STEIN, 2005).

Antibiotics production by microorganisms qualitatively and quantitatively depends on the strain of the producing microorganism as well as on the composition of the media and the biosynthesis conditions (MoITA et al., 2005). However, culture media is of critical importance, because variation of its composition can significantly affect antibiotics yield. Changes in the type and concentration of carbon, nitrogen, or phosphorus sources and of trace elements have influence on the antibiotic biosynthesis with Bacillus strains. Antibiotic production by Bacillus subtilis begins at the early stages of the stationary phase. Therefore, it is important to formulate the composition of the media, so that it favours their synthesis with limited

\footnotetext{
* To whom correspondence should be addressed. Phone: +381-21-485 3639; e-mail: jokic@uns.ac.rs
} 
growth of biomass. The carbon source needed for maximal production is different among producing microorganism strains and depends on the types of antibiotics (EL-BANNA, 2005). In recent years, glycerol, the main by-product of biodiesel production, is often used as carbon source in culture media. An increase in biodiesel production results in an increase in the amount of waste glycerol, which may be a huge problem, since it cannot be disposed of in the environment. Glycerol bioconversion in valuable products, such as antibiotics, reduces production costs and environmental problems caused by accumulation of this waste (DA SILVA et al., 2009). As nitrogen and phosphorus sources in media for antibiotics production different inorganic salts, such as ammonium salt, nitrates, nitrites, and phosphates are used. They are added in limited amounts because of the negative influence on the antibiotic biosynthesis. When the level of these nutrients in media is low, the rate of producing microorganism cells is slow and antibiotic synthesis is favoured (EL-BAnNA \& Quddoumi, 2007).

To achieve high antibiotics yield, it is necessary to properly define the composition of the culture media. Also, optimization of media is important from economic point of view, because production cost extensively depends on the media composition and the amount of the not-metabolised nutrients. Optimization of media by the traditional "one-factor-at-atime" technique requires a considerable amount of work and time. An alternative strategy is a statistical experimental design. Statistically designed experiments use a small set of carefully planned experiments. This method is more satisfactory and effective than others, because it can study many variables simultaneously with a low number of observations, saving time and costs (DEEPAK et al., 2008). In statistics-based approaches, response surface methodology (RSM) is a well-known method applied in the optimization of cultivation media for the production of antimicrobial agents effective against Staphylococcus aureus (EL-SERSY et al., 2009; GraHOVAC et al., 2013). RSM is a group of statistical techniques for designing experiments, building models, evaluating the effects of factors, and searching for the optimum conditions (Popov et al., 2010).

The aim of this study is optimization of medium composition in terms of glycerol, sodium nitrite, and phosphate content, by applying response surface methodology, for the production of compounds with antibacterial activity against Staphylococcus aureus. For antibiotics biosynthesis strain Bacillus subtilis ATCC 6633 was used.

\section{Materials and methods}

\subsection{Antibiotics producing microorganism}

As the producing microorganism strain, Bacillus subtilis ATCC 6633 was used in these experiments. The strain of producing microorganism was stored at $4{ }^{\circ} \mathrm{C}$ and subcultured every four weeks.

\subsection{Cultivation media}

In accordance with the defined aim and experimental plan of the study, in the media for antibiotic production contents of glycerol $\left(20 \mathrm{~g} \mathrm{l}^{-1} ; 35 \mathrm{~g} \mathrm{l}^{-1} ; 50 \mathrm{~g}^{-1}\right)$, sodium nitrite $\left(1 \mathrm{~g} \mathrm{l}^{-1} ; 2\right.$ $\left.\mathrm{g} \mathrm{l}^{-1} ; 3 \mathrm{~g} \mathrm{l}^{-1}\right)$, and phosphate in the form of $\mathrm{K}_{2} \mathrm{HPO}_{4}\left(5 \mathrm{~g} \mathrm{l}^{-1} ; 10 \mathrm{~g} \mathrm{l}^{-1} ; 15 \mathrm{~g} \mathrm{l}^{-1}\right)$ were varied. Media also contained $\left(\mathrm{g} \mathrm{l}^{-1}\right)$ : yeast extract $(0.5), \mathrm{CaCO}_{3}(17.0), \mathrm{MgSO}_{4} \times 7 \mathrm{H}_{2} \mathrm{O}(0.5)$, and $\mathrm{MnSO}_{4} \times 4 \mathrm{H}_{2} \mathrm{O}(0.05)$. The $\mathrm{pH}$ value of the media was adjusted to $7.0 \pm 0.1$ prior to sterilization by autoclaving at $121^{\circ} \mathrm{C}$ and pressure of 2.1 bars for $20 \mathrm{~min}$. 


\subsection{Biosynthesis conditions}

The biosynthesis of antibiotics was carried out in an Erlenmeyer flask (300 ml) containing $100 \mathrm{ml}$ of media. The inoculation was performed by adding $10 \%(\mathrm{v} / \mathrm{v})$ of inoculums prepared under aerobic conditions in nutrient broth at $28^{\circ} \mathrm{C}$ in a laboratory shaker at 150 r.p.m. for 48 $\mathrm{h}$. Antibiotic production was carried out under aerobic conditions at the temperature of $28^{\circ} \mathrm{C}$ and agitation rate of 150 r.p.m. for 4 days.

\subsection{Analytical methods}

At the end of the process, samples of cultivation media were centrifuged at $10000 \mathrm{~g}$ for 15 min (Eppendorf Centrifuge 5804, Germany). In the following work only the liquid phase of the cultivation media was used. Standard methods were used for the determination of residual glycerol (HautfenNe, 1982), total nitrogen (Herlich, 1990), and phosphorus (GALEs et al., 1966) contents.

Culture supernatants of each experiment were concentrated by evaporation on rotary vacuum evaporators (Ika-werke, Staufen) to one tenth of the initial mass and then were tested for their antibacterial activity. The antibacterial activity of obtained samples against Staphylococcus aureus ATCC 11632 was tested, in vitro, by diffusion-disc method (BAUER et al., 1966).

\subsection{Statistical analyses}

The selection of an experimental plan is a key step in the application of the RSM. In this study, experiments were carried out in accordance with Box-Behnken design with three factors on three levels and three repetitions in the central point. The factor variables and their values are: $\mathrm{X}_{1}$ : glycerol content $\left(20-50 \mathrm{~g}^{-1}\right.$, interval value $\left.15 \mathrm{~g} \mathrm{l}^{-1}\right), \mathrm{X}_{2}$ : sodium nitrite content (1-3 $\mathrm{g} \mathrm{l}^{-1}$, interval value $\left.1 \mathrm{~g} \mathrm{l}^{-1}\right)$, and $\mathrm{X}_{3}$ : phosphates content $\left(5-15 \mathrm{~g} \mathrm{l}^{-1}\right.$, interval value $\left.5 \mathrm{~g} \mathrm{l}^{-1}\right)$. For the description of the responses Y (residual glycerol $\left(\mathrm{g}^{-1}\right)$, residual nitrogen $\left(\mathrm{g}^{-1}\right)$, residual phosphorus $\left(\mathrm{g} \mathrm{l}^{-1}\right)$ ), and inhibition zone radius $(\mathrm{mm})$, a second degree polynomial model was fitted to the data:

$$
Y=b_{o}+\sum b_{i} X_{i}+\sum b_{i i}^{2} X_{i i}^{2}+\sum b_{i j} X_{i} X_{j}
$$

where $b_{0}$ represents intercept, $b_{i}$ represents the linear, $b_{i i}$ the quadratic and $b_{i j}$ the interaction effect of the factors.

Statistical analyses of experimental results were performed using Statistica software v. 12.0. Response surface plots were generated with the same software and drawn with a constant value of one of the parameters, while the remaining two parameters were varied. For determination of optimal values of examined factors, method of desirability function was applied (Design-Expert 8.1).

\section{Results and discussion}

\subsection{Statistical analyses of modelled responses}

In accordance with the aim of this study and applied experimental plan, media for antibiotics production were formulated by varying content of glycerol, sodium nitrite, and phosphate. 
For responses, obtained after these experiments, a polynomial model of the second degree was established to evaluate and quantify the influence of the variables. The adequacy of the model was evaluated by the determination coefficient $\left(\mathrm{R}^{2}\right)$ and model P-value. The results of the statistical analyses are presented in Table 1.

Table 1. Regression equation coefficients, their significance and determination coefficient for selected responses

\begin{tabular}{|c|c|c|c|c|c|c|c|c|}
\hline \multirow[t]{2}{*}{ Effects } & \multicolumn{2}{|c|}{ Residual glycerol } & \multicolumn{2}{|c|}{ Residual nitrogen } & \multicolumn{2}{|c|}{ Residual phosphorus } & \multicolumn{2}{|c|}{ Inhibition zone radius } \\
\hline & Coefficient & P-value & Coefficient & P-value & Coefficient & P-value & Coefficient & P-value \\
\hline \multicolumn{9}{|c|}{ Intercept } \\
\hline$b_{0}$ & -11.1413 & $0.0429^{*}$ & -0.0019 & 0.9892 & -0.1633 & 0.6603 & -36.2685 & $0.0497^{*}$ \\
\hline \multicolumn{9}{|l|}{ Linear } \\
\hline$b_{1}$ & 0.5906 & $0.0080^{*}$ & -0.0016 & 0.7348 & 0.0455 & $0.0117^{*}$ & 3.4963 & $0.0007^{*}$ \\
\hline$b_{2}$ & 1.7108 & 0.4137 & 0.1581 & 0.0586 & -0.2078 & 0.2573 & -0.5417 & 0.9372 \\
\hline$b_{3}$ & 0.3225 & 0.4392 & 0.0240 & 0.1233 & -0.0761 & 0.0662 & -2.1250 & 0.1654 \\
\hline \multicolumn{9}{|c|}{ Quadratic } \\
\hline$b_{11}$ & -0.0080 & $0.0052^{*}$ & 0.0001 & 0.5806 & -0.0005 & $0.0132^{*}$ & -0.0352 & $0.0017^{*}$ \\
\hline$b_{22}$ & -0.1321 & 0.7439 & 0.0058 & 0.6682 & 0.0152 & 0.6583 & -0.6667 & 0.6310 \\
\hline$b_{33}$ & -0.0041 & 0.8002 & -0.0007 & 0.2089 & 0.0036 & $0.0385^{*}$ & 0.0533 & 0.3536 \\
\hline \multicolumn{9}{|c|}{ Interaction } \\
\hline$b_{12}$ & 0.0205 & 0.4410 & -0.0007 & 0.4361 & -0.0015 & 0.5023 & -0.0833 & 0.3643 \\
\hline$b_{13}$ & 0.0006 & 0.9022 . & 0.0000 & 0.9999 & -0.0006 & 0.1848 & -0.0033 & 0.8497 \\
\hline$b_{23}$ & -0.1785 & 0.0595 & -0.0038 & 0.1815 & 0.0281 & $0.0062^{*}$ & 0.6000 & 0.0621 \\
\hline$R^{2}$ & \multicolumn{2}{|c|}{0.912} & \multicolumn{2}{|c|}{0.974} & \multicolumn{2}{|c|}{0.956} & \multicolumn{2}{|c|}{0.979} \\
\hline
\end{tabular}

*: Effect significant at $\mathrm{P}<0.05$ confidence level

Relatively high values of $\mathrm{R}^{2}$, obtained for all responses, indicate good fit of the experimental data to Equation 1. A P-value is used to assess the statistical significance for each of the regression equations' coefficients. Regression coefficients, with a significance level of $95 \%$, are significant if the value of their P-value is less than 0.05 . These coefficients are marked in Table 1.

The most significant response, for antibiotics yield, is inhibition zone radius against Staphylococcus aureus, because it is a direct indicator of the amount of synthesized antimicrobial compounds. For this response, coefficient of determination was found to be 0.979 , which indicates that only $2.1 \%$ of the variations could not be explained by the model. As for significance of the polynomial coefficients, their P-values suggest that the most important linear factor is initial content of glycerol, and the same conclusion can be applied to quadratic effects. Considering that carbon sources are involved in primary and secondary metabolism of microorganisms, these results are expected.

The response surface plots were generated to understand the interactions of the variables and to determine the optimum level of each variable to achieve the maximum response (Figs 
1, 2, and 3). Each figure represents the effects of two variables on the production of antimicrobial compounds effective against Staphylococcus aureus, whereas the third variable was maintained at constant value. These three dimensional plots provided a visual interpretation of the interaction between two factors and facilitated the location of the optimum experimental conditions.

Figure 1 shows the effects of initial content of glycerol and sodium nitrite at a constant concentration of phosphates $\left(10 \mathrm{~g} \mathrm{l}^{-1}\right)$ on the production of compounds with antibacterial activity against Staphylococcus aureus. From this figure it is evident that, in the applied experimental conditions, the inhibition zone radius for all concentrations of glycerol does not depend on the initial sodium nitrite content. For all used initial concentrations of sodium nitrite, the increase in the amount of glycerol produced an increase of the selected response from about $5 \mathrm{~mm}$ to about $35 \mathrm{~mm}$. This can be explained by the fact that nitrogen in the media stimulates the biomass growth but not the biosynthesis of secondary metabolites such as antibiotics.

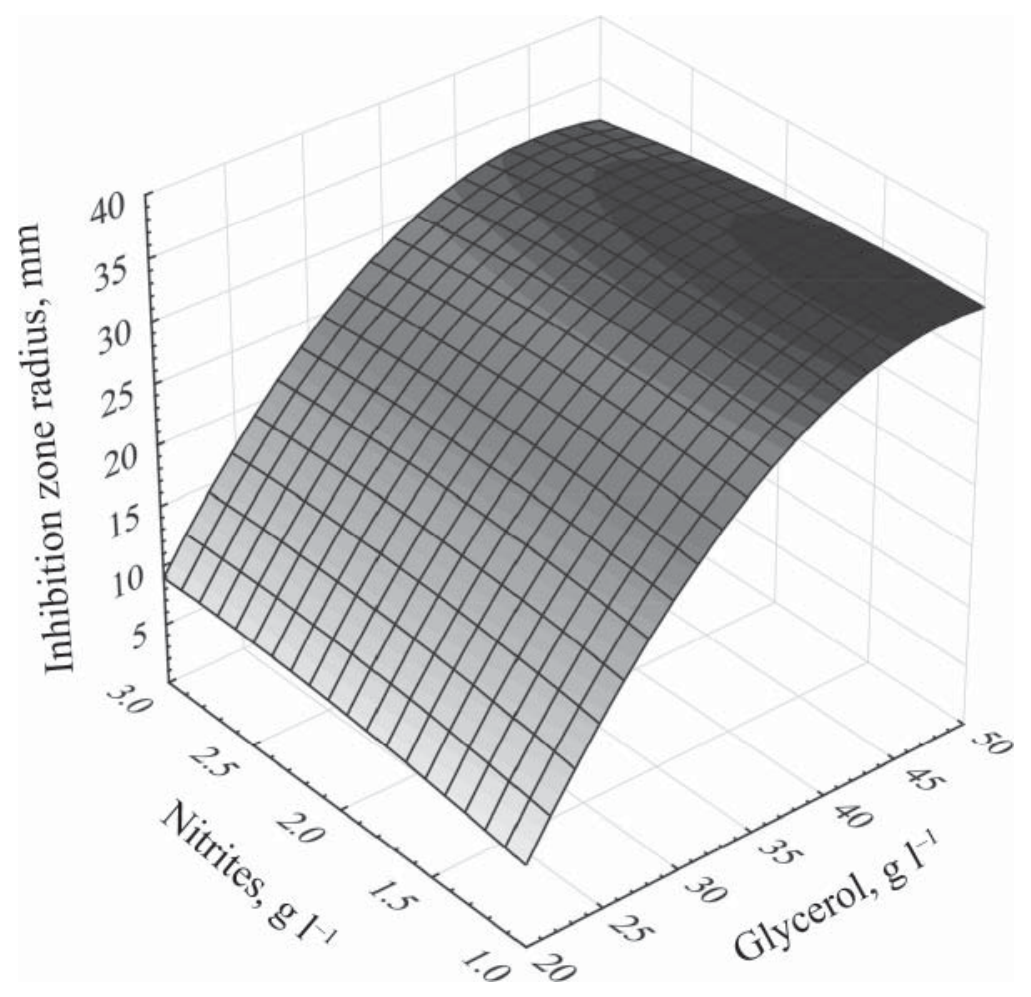

Fig. 1. The effects of initial contents of glycerol and sodium nitrite on inhibition zone radius for Staphylococcus aureus at constant value of phosphates $\left(10 \mathrm{~g} \mathrm{l}^{-1}\right)$

The effects of the initial contents of glycerol and phosphates on inhibition zone radius for Staphylococcus aureus at constant value of sodium nitrite $\left(2 \mathrm{~g} \mathrm{l}^{-1}\right)$ are presented in Figure 2. As in the previous case, results suggest that inhibition zone radius only depends on the 
initial glycerol concentration. Therefore, in applied experimental conditions, glycerol, as a carbon source, is the most important nutrient in media for the production of antibiotics effective against the selected test microorganism.

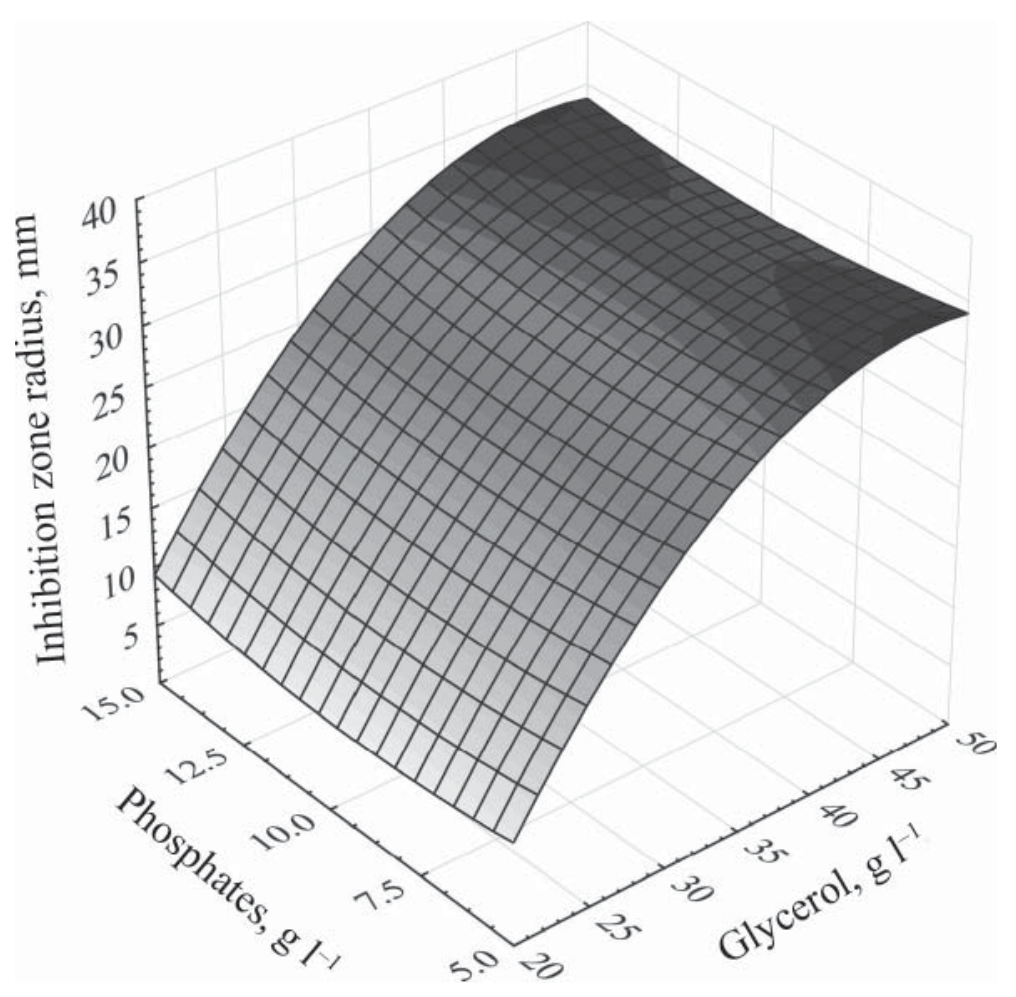

Fig. 2. The effects of initial contents of glycerol and phosphates on inhibition zone radius for Staphylococcus aureus at constant value of sodium nitrite $\left(2 \mathrm{~g} \mathrm{l}^{-1}\right)$

The influence of initial sodium nitrite and phosphates contents on the biosynthesis of compounds effective against Staphylococcus aureus at constant concentration of glycerol $\left(35 \mathrm{~g} \mathrm{l}^{-1}\right)$ is shown in Figure 3. As it can be seen from the figure, the increase in the sodium nitrite content at the minimal initial concentration of phosphates results in the minimum inhibition zone radius of about $20 \mathrm{~mm}$, while the maximum initial amount of phosphates gives the reverse result, the maximum inhibition zone radius of about $30 \mathrm{~mm}$. When the medium values of sodium nitrite were used, no significant effect of phosphates on the selected response was observed. It can be noticed that for the highest production of antibiotics, in the applied experimental condition, one must use the lowest content of sodium nitrite and phosphates ( $1 \mathrm{~g} \mathrm{l}^{-1}$ and $5 \mathrm{~g} \mathrm{l}^{-1}$, respectively) or the highest content of both nutrients $\left(3 \mathrm{~g} \mathrm{l}^{-1}\right.$ of sodium nitrite and $15 \mathrm{~g} \mathrm{l}^{-1}$ of phosphates). 


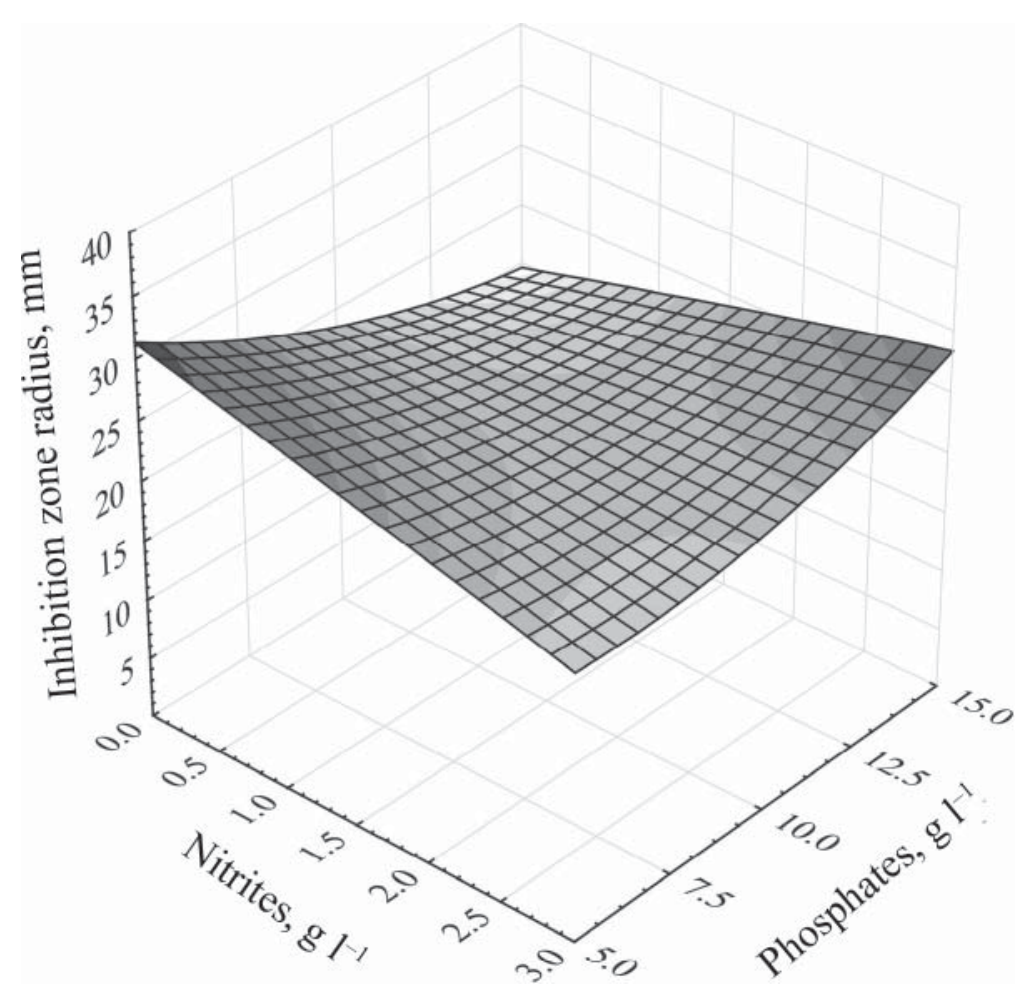

Fig. 3. The effects of initial contents of sodium nitrite and phosphates on inhibition zone radius for Staphylococcus aureus at constant value of glycerol $\left(35 \mathrm{~g} \mathrm{l}^{-1}\right)$

\subsection{Optimization of antimicrobial compounds production}

The final goal of response surface methodology is the process optimization. Thus, the developed models can be used for simulation and optimization. To optimize the process with two or more output responses, it is helpful to use the concept of desirability function (D). The desirability function is one of the most widely used methods for optimization of multiple response processes in science and engineering. It combines multiple responses into one response called desirability function by choice of value from 0 (one or more characteristics are unacceptable) to 1 (all process characteristics are on target). Each of the estimated responses is transformed to an individual desirability value ranging from 0 to 1 . The value of individual desirability increases as the desirability of the corresponding response increases. The overall desirability of the process is computed as geometric mean of the individual desirability functions (GraHOvAC et al., 2012).

In this study, four responses were used for optimization of antibiotics production, i.e. maximization of inhibition zone radius against Staphylococcus aureus, while residual contents of glycerol, total nitrogen, and phosphorus were minimized. Effects of glycerol and sodium nitrite contents on the value of desirability function at the optimal phosphate content 
$\left(5 \mathrm{~g} \mathrm{l}^{-1}\right)$ are presented in Figure 4. As it can be seen from Figure 4, the highest values of desirability function are obtained in the region of high initial glycerol content and low initial sodium nitrite content. The optimal values of initial content of glycerol, sodium nitrite, and phosphate are $49.99 \mathrm{~g} \mathrm{l}^{-1}, 1.00 \mathrm{~g} \mathrm{l}^{-1}$, and $5.00 \mathrm{~g} \mathrm{l}^{-1}$, respectively, for the highest value of desirability function (0.958). The optimal response values for selected initial nutrient contents are $38.08 \mathrm{~mm}, 1.75 \mathrm{~g} \mathrm{l}^{-1}, 0.21 \mathrm{~g} \mathrm{l}^{-1}$, and $0.18 \mathrm{~g} \mathrm{l}^{-1}$ for inhibition zone radius against test microorganism and residual content of glycerol, nitrogen, and phosphorus, respectively. Minimal optimal contents of sodium nitrite and phosphate confirm that the nitrogen and phosphorus are commonly the major growth-limiting nutrients and play important role in the onset and intensity of secondary metabolism in which antimicrobial compounds are synthesized (SANCHEZ \& DEMAIN, 2002).

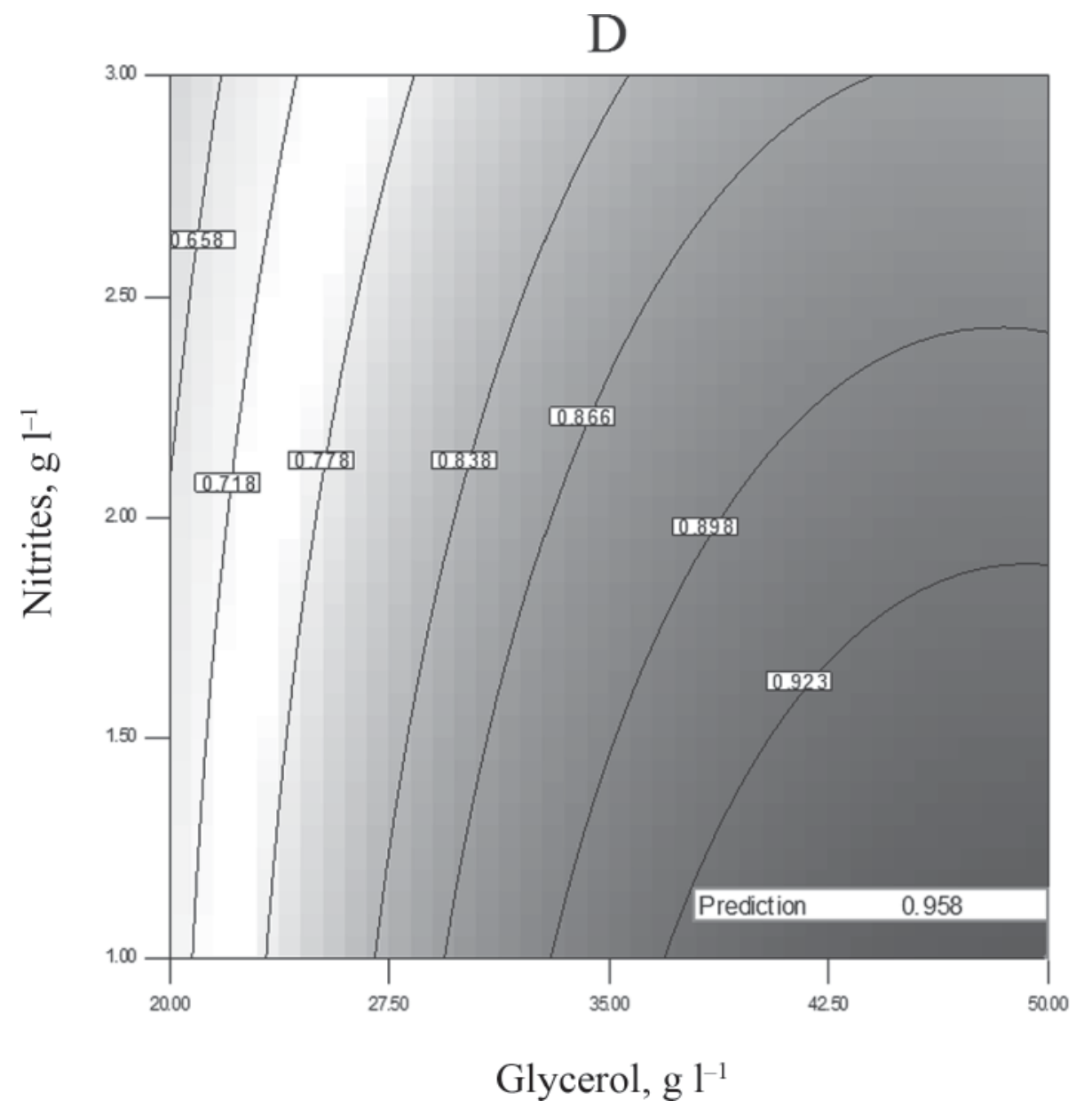

Fig. 4. The overall desirability function of the antibiotics production process 


\section{Conclusions}

This research has confirmed that Bacillus subtilis ATCC 6633 has great potential for the production of antimicrobial compounds effective against Staphylococcus aureus. Response surface methodology proved to be an efficient tool for optimizing process conditions, it is relatively simple and time and material saving. The regression equations obtained in this study can be used to find optimum conditions for antimicrobial compounds production at an industrial scale from economic point of view.

This work was financially supported by the Provincial Secretariat for Science and Technological Development, Autonomous Province of Vojvodina, Project Number: 114-451-5041/2013.

\section{References}

Bauer, A.W., Kirby, W.M.M., Sherris, J.C. \& Turck, M. (1966): Antibiotic susceptibility testing by a standardized single disk method. Am. J. Clin. Pathol., 45, 493-496.

DA Silva, G.P., Mack, M. \& Contiero, J. (2009): Glycerol: A promising and abundant carbon source for industrial microbiology. Biotechnol. Adv., 27, 30-39.

Deepak, V., Kalishwaralal, K., Ramkumarpandian, S., Venkatesh Babu, S., Senthilkumar, S.R. \& Sangiliyandi, G. (2008): Optimization of media composition for Nattokinase production by Bacillus subtilis using response surface methodology. Bioresource Technol., 99, 8170-8174.

El-Banna, N.M. (2005): Effect of carbon source on the antimicrobial activity of the air flora. World J. Microbiol. Biot., 21, 1451-1454.

El-Banna, N.M. \& Quddoumi, S.S. (2007): Effect of nitrogen source on the antimicrobial activity of the bacilli air flora. Ann. Microbiol., 57, 669-671.

El-Sersy, N.A., Ebrahim, H.A.H \& Abou-Elela, G.M. (2009): Response surface methodology as a tool for optimizing the production of antimicrobial agents from Bacillus licheniformis SN2. Curr. Res. Bacteriol., 3, $1-14$.

Gales, M.E. JR., Julian, E.C. \& Kroner, R.C. (1966): Method for quantitative determination of total phosphorus in water. J. Am. Water Works Ass., 58, 1363-1368.

Grahovac, J., Dodić, J., Jokić, A., Dodić, S. \& Popov, S. (2012): Optimization of ethanol production from thick juice: A response surface methodology approach. Fuel, 93, 221-228.

Grahovac, J.A., Bajić, B.Ž., Dodić, J.M., RončEvić, Z.Z. \& Jokić, A.I. (2013): Optimization of cultivation medium for the production of antibacterial agents. Acta Periodica Technologica, 44, 217-227.

Hautfenne, A. (1982): Standard methods for the analysis of oils, fats and derivatives. Pure Appl. Chem., 54, 12571295.

Herlich, K. (Ed.) (1990): Official methods of analysis of the association of official analytical chemists. 5th ed., Association of Official Analytical Chemists, Arlington, pp. 758-759.

KutA, F.A., Nimzing, L. \& OrkA'A, P.Y. (2009): Screening of Bacillus species with potentials of antibiotics production. Appl. Med. Inform., 24, 42-46.

Moita, C., Feio, S.S., Nunes, L., Curto, M.J.M. \& Roseiro, J.C. (2005): Optimisation of physical factors on the production of active metabolites by Bacillus subtilis 355 against wood surface contaminant fungi. Int. Biodeter. Biodegr., 55, 261-269.

Popov, S., Ranković, J., Dodić, J., Dodić, S. \& Jokić, A. (2010): Bioethanol production from raw juice as intermediate of sugar beet processing: A response surface methodology approach. Food Technol. Biotech., 48, 376-383.

SAnchez, S. \& Demain, A.L. (2002): Metabolic regulation of fermentation processes. Enzyme Microb. Tech., 31, 895-906.

Stein, T. (2005): Bacillus subtilis antibiotics: structures, syntheses and specific functions. Mol. Microbiol., 56, 845857.

Tabbene, O., Slimene, I.B., Bouabdallah, F., Mangoni, M.L., Urdaci, M.C. \& Limam, F. (2009): Production of antimethicillin-resistant Staphylococcus activity from Bacillus subtilis sp. strain B38 newly isolated from soil. Appl. Biochem. Biotech., 157, 407-419.

Todorova, S. \& Kozhuharova, L. (2010): Characteristics and antimicrobial activity of Bacillus subtilis strains isolated from soil. World J. Microbiol. Biot., 26, 1207-1216. 